\title{
Population dynamics of Capitella capitata (Polychaeta; Capitellidae) in an organically polluted cove
}

\author{
Hiroaki Tsutsumi
}

Amakusa Marine Biological Laboratory, Kyushu University, Tomioka, Reihoku-cho, Amakusa, Kumamoto-ken, Japan 863-25

\begin{abstract}
The population dynamics of a sibling species of Capitella capitata (Fabricius) in a cove organically polluted by fish farming were characterized by early recolonization in azoic areas, very rapid population growth, and extinction following development of extremely anaerobic conditions during summer. The remarkably high potential for population growth results from the short life cycle and continual reproduction as a population. Previously, the production of planktonic larvae with the ability to disperse over a wide area was considered one of the most important life history characteristics of opportunistic polychaetes in unpredictable habitats. In the present study, however, Capitella sp. exhibited opportunistic population dynamics during benthic recovery after defaunation in heavily polluted areas, despite production of a small number of large eggs with restricted dispersal ability via lecithotrophic larvae. The size composition of the recolonizing population suggested that some of the worms were recruited as mature adults from a very small population maintained in the immediate vicinity of the sampling station in an environment disturbed by organic pollution. Although the population dynamics of Capitella sp. appear to be characteristic of highly opportunistic organisms, results suggest that populations may be maintained within each habitat by reliance only on a remarkably large potential for population growth. In general, organically polluted areas may not be temporary habitats that Capitella sp. can utilize only during benthic recovery immediately after defaunation, but rather such areas may be their native habitats.
\end{abstract}

\section{INTRODUCTION}

The general distribution of benthic macrofauna and sediments along a gradient of organic enrichment has been revealed by benthic studies of organically polluted areas over the past 2 decades (Kitamori 1975, Pearson \& Rosenberg 1976, 1978, Reish 1979). Benthic communities in the most polluted areas are not diverse. Only a few species of small polychaetes Capitella capitata and some spionids (Scolelepsis fuliginosa, Paraprionospio pinnata, Polydora ligni etc.), predominate. In particular, C. capitata occurs at high densities only in heavily polluted areas throughout the world (Reish 1971, 1979, Rosenberg 1972, 1976, Wade et al. 1972, Halcrow et al. 1973, Grassle \& Grassle 1974, Pearson \& Rosenberg 1978, Yamamoto 1980, Tsutsumi \& Kikuchi 1983). Bottom water and sediment in organically polluted areas are apt to become anaerobic in summer, because of accelerated decomposition of abundant organic matter and stagnation of the bottom water. Although the occurrence of extremely deoxyge- nated conditions often results in temporary defaunation, only the predominant polychaetes, C. capitata and the spionid polychaetes, can recolonize azoic areas quickly and restore their populations to their earlier sizes in a short period of time during the process of benthic faunal recovery after defaunation (Kolmel 1979, Yamamoto 1981, Tsutsumi \& Kikuchi 1983). C. capitata is not more tolerant of extreme hypoxia than the dominant species in semi-healthy zones (Reish 1966) or in less polluted areas (Ueno \& Yamamoto 1982). In recent years, the exclusive domination of $C$. capitata in organically polluted areas has been recognized to be a reflection of its life history characteristics, in particular its adaption to unpredictable environments, rather than of its tolerance of hypoxia (Warren 1984).

The rapid recovery of Capitella capitata after environmental disturbance has also been reported in a follow-up study of benthic communities seriously damaged by an oil spill (Grassle \& Grassle 1974). McCall (1977) indicated that $C$. capitata, together with the 
spionid polychaete Streblospio benedicti, recolonized early in experimental boxes of azoic sediments. Thus, early recolonization and rapid population growth are notable life history characteristics of $C$. capitata in disturbed habitats, and are properties similar to those of other opportunistic species (Grassle \& Grassle 1974 , 1976, McCall 1977).

However, studies of the life history of Capitella capitata (Wu 1964, Bellan et al. 1972, Foret 1974, Reish 1974, Grassle \& Grassle 1976, Warren 1976a, Kikuchi 1979, Yamamoto 1980, Tsutsumi \& Kikuchi 1984. unpubl.), electrophoretic analysis (Grassle \& Grassle 1976), and chromosomal studies (Grassle et al. in press), have indicated that this species actually consists of numerous sibling species, with similar adult morphologies but distinct reproductive modes, that generally occur in different geographic regions, but occasionally occur sympatrically (Grassle \& Grassle 1976, 1977). Their characteristics differ greatly; the differences in colonizing ability among the sibling species reflect differences in the environmental variability of their respective habitats (Grassle 1980). Hence, there is only a limited number of species in the whole sibling species complex of $C$. capitata that occur in disturbed habitats and which exhibit highly opportunistic properties.

Life history strategies of Capitella species that occur in disturbed habitats have been studied in the last decade. Early studies (Grassle \& Grassle 1974, McCall 1977) categorized the life history strategies of these sibling species as opportunistic (or r-strategist, as defined by Wilson \& Bossert 1971) or fugitive (sensu Gadgil \& Solbrig 1972) etc. The term 'fugitive (opportunistic)' stresses the ability of planktonic larvae to disperse over a wide area, one of the most important life history characteristics of the Capitella species which allows them to discover open, short-lived, habitats and to establish a population quickly. Recent life history studies, however, have shown that these sibling species produce few large eggs, and have rather limited ability to disperse by means of pelagic lecithotrophic larvae. Furthermore, other species of Capitella, which produce many small eggs and have the greatest powers of larval dispersal, in fact occur in less variable habitats (Grassle \& Grassle 1976, 1977, 1978, Grassle 1980, Tsutsumi \& Kikuchi 1983). The relationship between the life history characteristics of the sibling species of Capitella and the predictability of environmental conditions in their habitats contradicts predictions made by models of life history strategy. Apparently, descriptions of the life history strategies of Capitella species that occur in disturbed habitats require revision, which may also help to elucidate life history characteristics of other marine invertebrates that are favored in unstable environments, and the evolutionary implications of such characteristics.

I have studied seasonal fluctuations of the benthic communities and the life history and population dynamics of a Capitella species in a cove, Tomoe Cove, organically polluted by fish farming in Amakusa, South Japan, since 1978 (Tsutsumi 1983, Tsutsumi \& Kikuchi 1983, 1984). Field and laboratory studies on Capitella sp. indicate a constancy in the size of mature eggs throughout the year, and no marked changes in brood size per female that cannot be accounted for by concommitant changes in the body size of brooding females. I have, therefore, concluded that a single species of Capitella is represented in the population in the present study area, and it is referred to here as Capitella capitata. In general, the features of its life history closely resemble those of Capitella sp. I which has the most rapid response following environmental disturbance (Grassle \& Grassle 1976, Grassle 1980).

The aims of the present study were to analyse the population dynamics of Capitella capitata in the organically polluted cove, and to elucidate the mechanisms that contribute to the rapid growth of the population after recolonization, and those that allow this species to maintain its population in the cove with the environmental conditions disturbed by organic enrichment.

I also investigated the population dynamics of Capitella capitata on the muddy flat, Shioiri Flat, adjacent to Tomoe Cove. Here, samples of C. capitata were collected throughout the year, although seasonal fluctuations in population density are quite large (Tsutsumi 1983). These results will be reported elsewhere.

\section{STUDY AREA}

Tomoe Cove is a subsidiary cove of Tomioka Bay which is located on the northwestern corner of Amakusa Shimoshima Island, on the west coast of Kyushu, Japan ( $32^{\circ} 32^{\prime} \mathrm{N}, 130^{\circ} 02^{\prime} \mathrm{E}$ ) (Fig. 1a). The cove is semienclosed by a narrow sand spit and the mouth of the cove is shallower than the cove itself. Thus, the influence of Bay water on the cove is minimal. Seasonal variation in bottom water temperature in the cove was from about $12.9^{\circ} \mathrm{C}$ in February to $24.9^{\circ} \mathrm{C}$ in August (Fig. 2). Fish farming is carried out in the eastern part of the cove (hatched area in Fig. 1a, b). Red sea bream Pagrus major are reared in floating net cages and fed with anchovies. Fish faeces and uneaten food residues disperse, or sink to the bottom, resulting in a large organic contribution to the bottom water and sediment of the cove. Depletion of dissolved oxygen occurs in the cove bottom water every summer, because of increased degradation of organic matter and limited water renewal. 


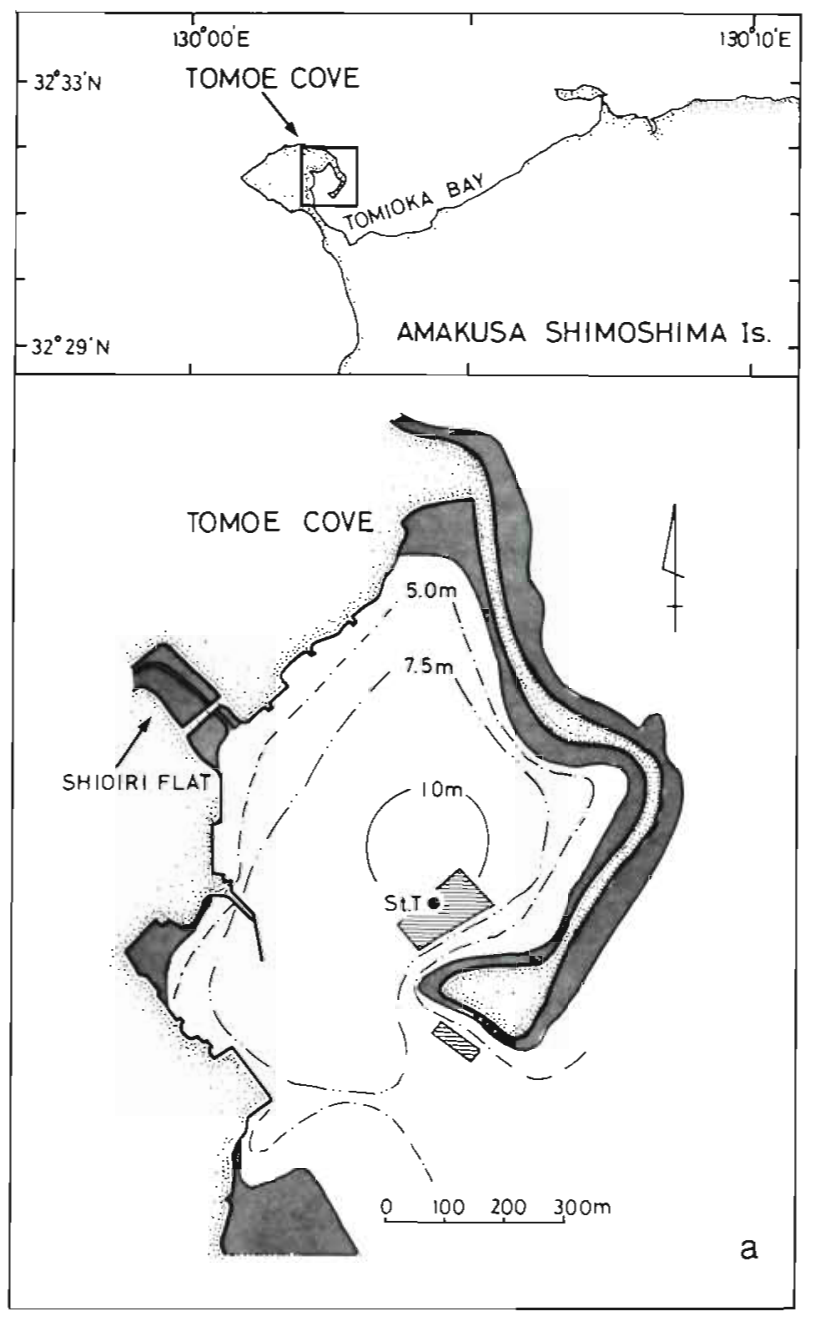

Sediments in the present study area were classified by their silt-clay content (The Meteorological Agency of Japan 1970). The bottom sediment of Tomoe Cove could be separated into 3 types based on grain size: (1) a homogeneous mud bottom (silt-clay content of the sediment $>75 \%$ ) inside the cove; (2) a sandy mud (siltclay content 50 to $75 \%$ ); and (3) a muddy sand bottom (silt-clay content between 25 and $50 \%$ ). The sandy mud and muddy sand were found at the mouth and outside the cove.

\section{MATERIALS AND METHODS}

The abundance of Capitella capitata was estimated at 10 sampling stations in Tomoe Cove (Fig. 1a) on 1 May 1979 and at 23 stations around the floating cages used for fish farming in the eastern part of the cove (Fig. 1b) on 17 May, 22 August, and 23 September 1980. One of these stations, Stn T, located inside the fish farm, was selected for the population study. Samples were taken at fortnightly or monthly intervals

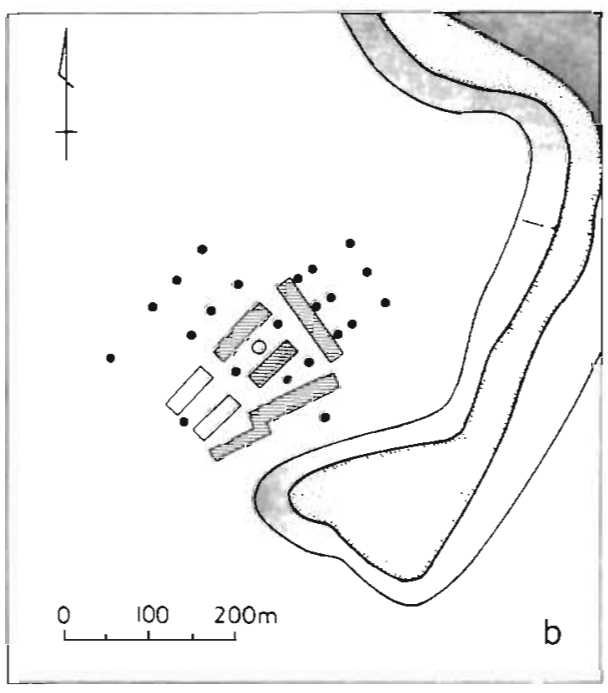

Fig. 1. Study area, Kyushu, Japan. (a) Topography and bathymetry. (b) Locations of sampling stations in Tomoe Cove: (o) stations where the distribution of Capitella capitata was studied; (O) station (Stn T) used for the population study. Hatched areas: cages used in fish farming; open rectangles: unused cages; dark areas: intertidal zone

from November 1979 to April 1980, and 4 to 6 times per month from May 1980 to February 1981. At Stn T, samples of bottom water, for measurement of dissolved oxygen, and samples of surface sediment, for measurement of total sulphide, were taken 2 to 5 times per month from May to December 1980. Dissolved oxygen was measured by Winkler's method; total sulphide was determined using an $\mathrm{H}_{2} \mathrm{~S}$ absorbent column tube ('Hedorotec', Kitazawa Sangyo Co. Ltd.).

Sediment samples were taken with an Ekman-Birge bottom sampler $(20 \mathrm{~cm} \times 20 \mathrm{~cm})$ from a boat. Four grab samples were collected at each station in the survey on 1 May 1979. Samples were sieved on $1.0 \mathrm{~mm}$ mesh screen on the boat, and the residues were fixed in a $10 \%$ formalin solution containing Rose Bengal. During sampling on 17 May, 22 August, and 23 September 1980 , at least 3 grab samples were taken at each

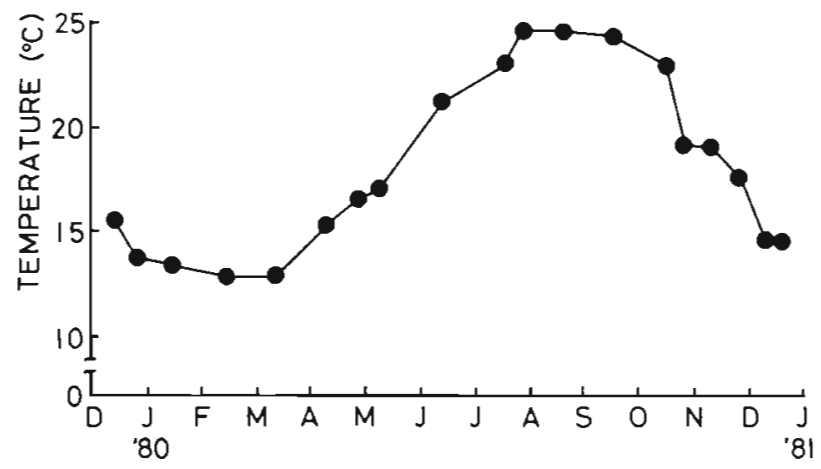

Fig. 2. Seasonal temperature variations in bottom water at Stn $\mathrm{T}$, Tomoe Cove 
station, and 5 subsamples were collected from each of them with a small corer $(6.25 \mathrm{~cm} \times 6.25 \mathrm{~cm} \times 5 \mathrm{~cm})$. The sediment samples were brought back to the laboratory, fixed in a $10 \%$ formalin solution containing Rose Bengal, and sieved on $0.5 \mathrm{~mm}$ mesh screen. Samplings at Stn T were carried out in almost the same manner as that described above, but 10 to 20 subsamples were prepared on each occasion, and sieved on $0.125 \mathrm{~mm}$ fine mesh screen. Since Capitella capitata juveniles just after settlement have a body size between 0.14 and $0.16 \mathrm{~mm}$ in thoracic width, all of the specimens in the samples should be retained on the $0.125 \mathrm{~mm}$ mesh screen. The worms were sorted and counted under a stereomicroscope and preserved in $10 \%$ formalin solution.

The sex of adult worms was determined by examination of the morphology of the notosetae in the 8th and 9th thoracic setigers. The maximum thoracic width of Capitella capitata was taken as the measure of body size since it is closely correlated with dry body weight (Tsutsumi \& Kikuchi 1984). Thoracic setigers are stout and were never injured during sampling and processing. Specimens were placed under a stereomicroscope equipped with a camera lucida, and their magnified images $(30 \times)$ projected onto paper set under the camera lucida. The maximum thoracic widths (usually the 5 th or 6 th setiger is widest) of the projected images were recorded as 2 pin holes on the paper. The distan-

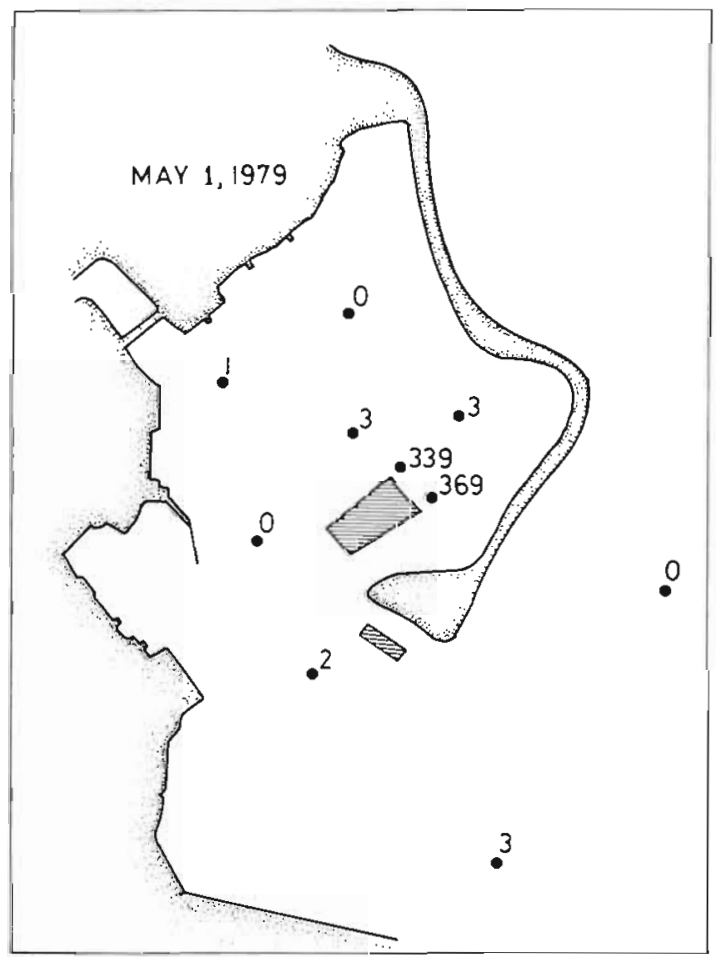

Fig. 3. Capitella capitata. Distribution (ind $0.16 \mathrm{~m}^{-2}$ ) in Tomoe Cove on 1 May 1979. Hatched areas: cages used in fish farming. (Samples sieved on a $1.0 \mathrm{~mm}$ screen)

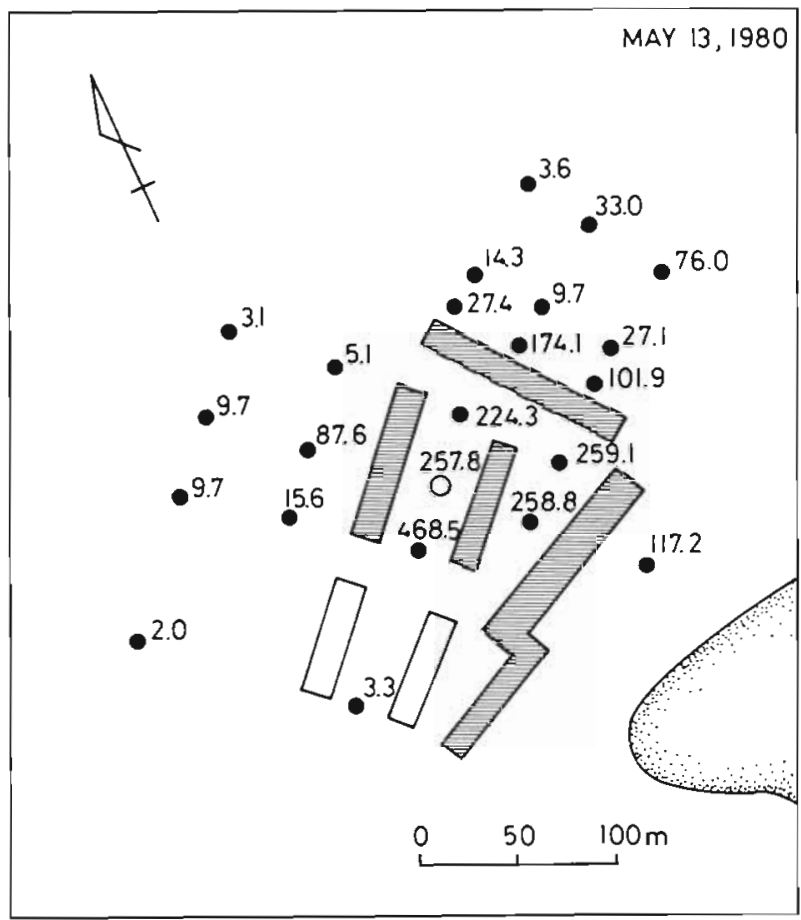

Fig. 4. Capitella capitata. Distribution (ind $0.01 \mathrm{~m}^{-2}$ ) around the fish farming cages (hatched areas) in Tomoe Cove on 13 May 1980. (Samples sieved on a $0.5 \mathrm{~mm}$ screen). (O) Station (Stn T) used in the population study

ces between the pin holes were measured by a graphic digitizer (Gradimate, Oscon) connected to a microcomputer (Multi 16, Mitsubishi Electric Co.), and the actual maximum thoracic widths of the specimens were calculated and stored on floppy disc.

Analysis of the generation structure of the Capitella capitata population was also performed using a computer. The size-frequency distribution of the population was calculated from the body size data stored on the floppy disc, and the results were plotted by computer. Polymodal distributions of size frequency were divided into monomodal ones by a modified version of the graphic methods of Cassie (1954) and Taylor (1965), programmed in Basic 86 (Tsutsumi unpubl.).

\section{RESULTS}

\section{Distribution and abundance}

The study of the Capitella capitata population in Tomoe Cove has been in progress since 1979. The cove has been organically polluted by fish farming for the past decade. Fig. 3 shows the abundance of C. capitata (ind $0.16 \mathrm{~m}^{-2}$ ) at 10 sampling stations in the cove on 1 May 1979. The highest densities occurred at the most organically polluted stations, adjacent to the source of the organic discharge. 
Distribution of this dense population was investigated in more detail in spring 1980, since benthic communities in the cove tend to become most abundant in spring (Tsutsumi \& Kikuchi 1983). Fig. 4 shows the abundance of Capitella capitata at 23 stations around the floating cages on 13 May 1980. The highest densities $\left(>25000 \mathrm{~m}^{-2}\right)$ were found in the immediately vicinity of the fish farming cages, i.e. the source of pollution, but quickly diminished at stations a short distance away.

Seasonal fluctuations in population density at Stn $T$ are shown in Fig. 5. The highest density in 1980 (about $47000 \mathrm{~m}^{-2}$ ) was recorded in May. The population had completely disappeared by July, when conditions on the bottom became extremely reduced (Fig. 6). The concentration of dissolved oxygen in the bottom water

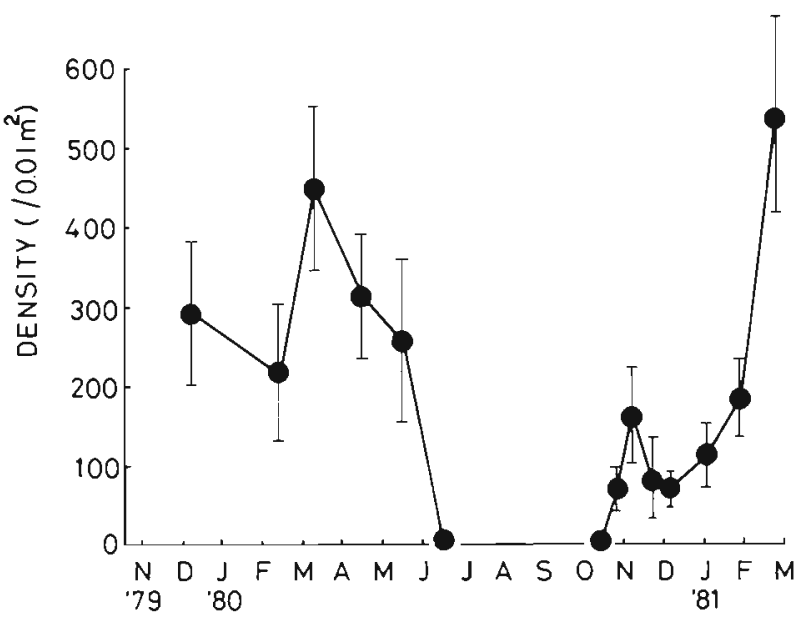

Fig. 5. Capitella capitata. Seasonal fluctuations of density (ind $0.01 \mathrm{~m}^{-2}, \overline{\mathrm{x}} \pm \mathrm{SD}, \mathrm{n}=10$ ) at $\mathrm{Stn} T$. Tomoe Cove. (Samples sieved on a $0.125 \mathrm{~mm}$ screen)
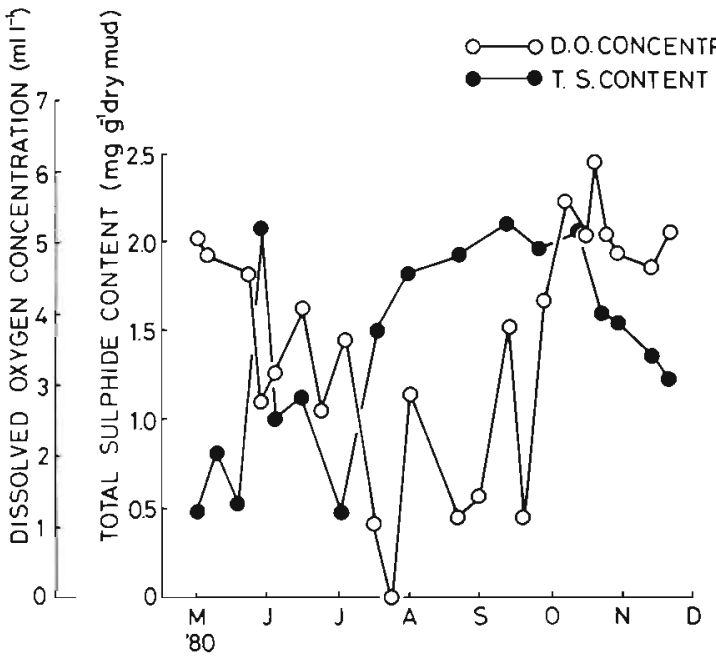

Fig. 6. Measurements of the concentration of dissolved oxygen (D. O.) in the bottom water and total sulphide content ( $T$. S.) in the sediment at Stn T, Tomoe Cove, during the summer stratification period at Stn T fluctuated throughout the summer but generally remained below $1 \mathrm{ml} \mathrm{l}^{-1}$ from July to September. Large amounts of total sulphides, including hydrogen sulphide, accumulated in the sediment following the depletion of dissolved oxygen (Fig. 6). The dense population of Capitella capitata in the heavily polluted area disappeared in July and the organisms did not begin to re-establish themselves until late October when the concentration of dissolved oxygen increased, and the sulphide content of the sediment began to fall. A survey of 23 stations around the fish farming cages (Fig. 1b) on 22 August and 23 September 1980 revealed no $C$. capitata. Additionally, 28 stations in the cove were sampled in mid-July 1981 and 8 stations in the cove were sampled in mid-July 1985. During both summers, no specimens of $C$. capitata were found. When C. capitata recolonized Stn T in October 1980 (Fig. 5), the population showed a remarkably high potential for growth, reaching a density of more than $50000 \mathrm{~m}^{-2}$ within $3 \mathrm{mo}$.

\section{Size composition of a recolonizing population}

Sampling at Stn $T$, at approximately weekly intervals, was carried out from May to December 1980 to determine the population dynamics of Capitella capitata. No specimens were found up to and including 3 October, since extinction of the population in midJune. Recolonization by $C$. capitata was first observed in samples taken on 12 October. Changes in the size distribution at Stn $\mathrm{T}$ are shown in Fig. 7. Recolonization was indicated by the discovery of a single brooding female (a female brooding embryos in a brood tube) in one of a total of 20 cores $\left(800 \mathrm{~cm}^{2}\right)$. On 21 October, 73 juvenile worms were found with 3 adults (one brooding female and 2 fully mature males) in 20 cores.

It is noteworthy that some adult worms were included in the colonizing population. Extremely anaerobic conditions in the bottom water and sediment persisted until late September at this station (Fig. 6). It is therefore probable that these adult worms did not migrate to the site of recolonization as planktonic larvae. Capitella capitata is a sedentary polychaete with limited mobility. The worms burrow slowly through the sediment. Although no remnants of the population were discovered during the summer within several hundred meters of the fish farm, in spite of intensive sampling, the presence of adult worms in the recolonizing population at Stn $T$ suggests that a very small population was maintained throughout the summer somewhere close to this station. It is possible that the first recruits at $\operatorname{Stn} T$ (73 juveniles) collected on 21 October (Fig. 7) may have been derived from the larvae 

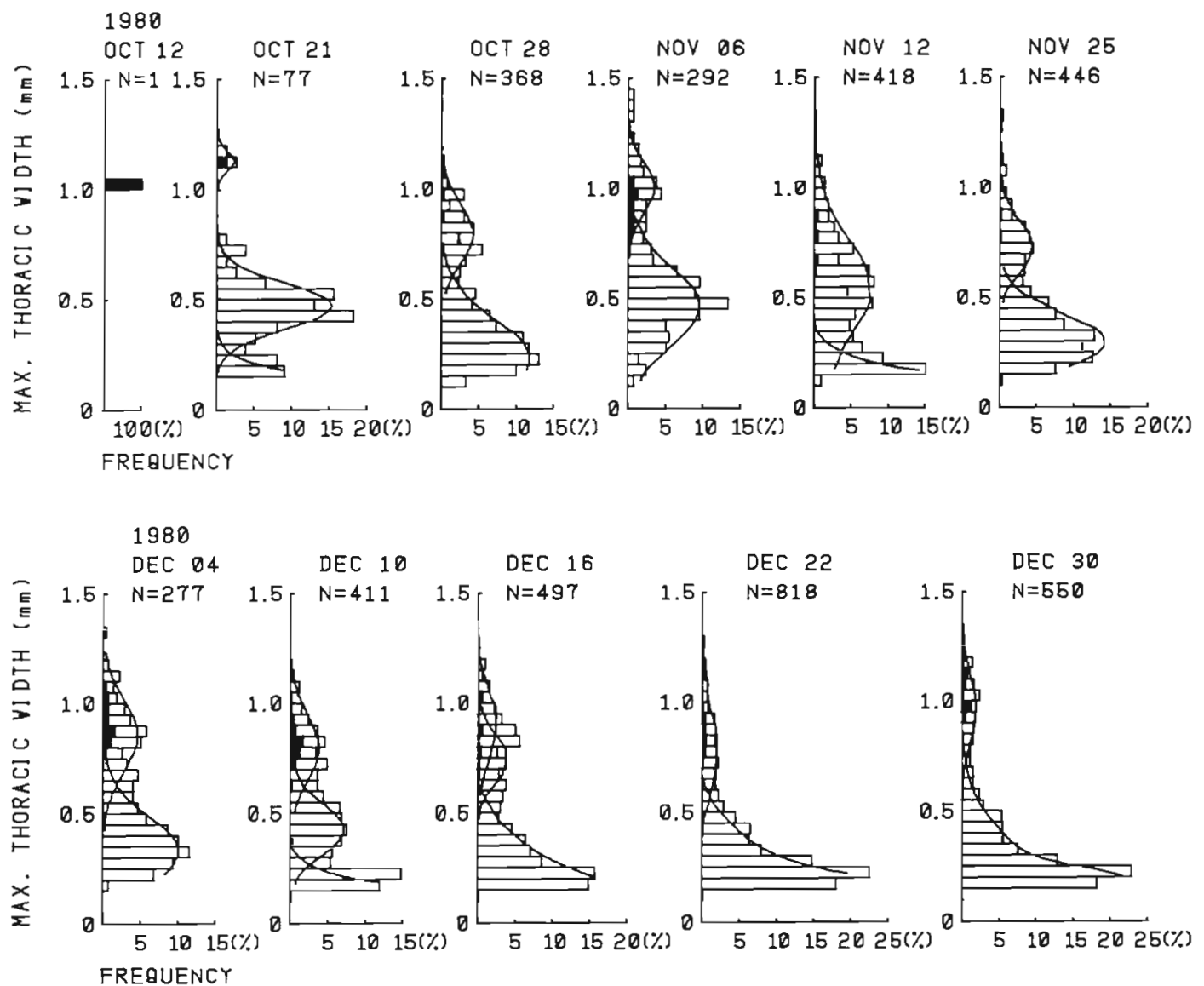

Fig. 7. Capitella capitata. Size-frequency distributions of the recolonizing population. Filled bars: brooding females

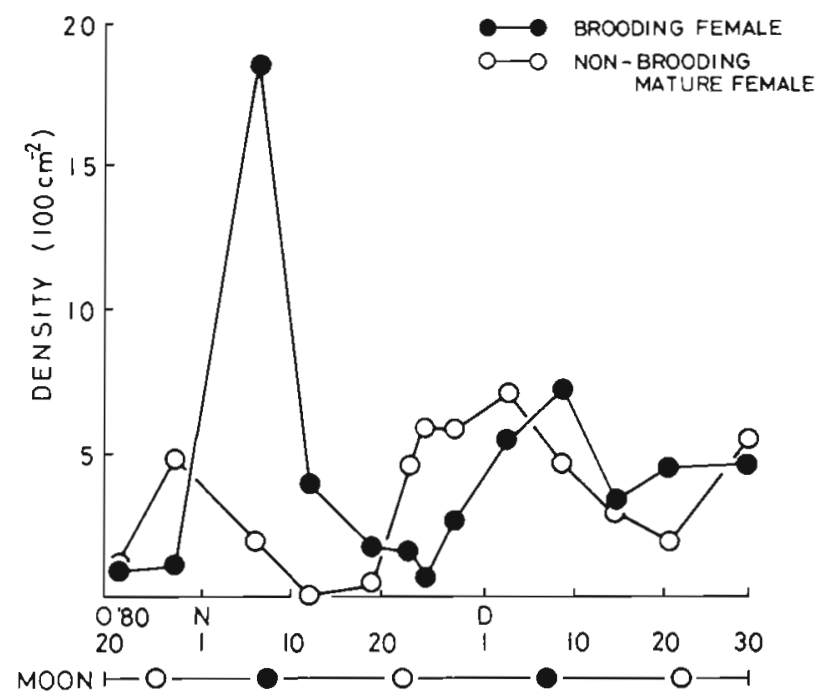

Fig. 8. Capitella capitata. Monthly density fluctuations of brooding females and non-brooding mature females, Oct to Dec 1980

in the brood tubes of these surviving adults. Brooding females with thoracic widths of more than $1.0 \mathrm{~mm}$, collected on 12 and 21 October, produced between 300 and 400 larvae. Such relatively small brood sizes may be too small to compensate for the larval loss that accompanies widespread dispersal at the larval pelagic stage.

The timing of reproduction in the Capitella capitata population appears to be synchronous with spring tide. Fig. 8 shows the densities of brooding and non-brooding females, and the lunar cycle from October to December 1980 . The density of brooding females reached a peak twice during these 3 months (on 6 Nov and $10 \mathrm{Dec})$, although the second peak was less pronounced. Both in the laboratory colonies and in the field populations, almost all of the females which were brooding larvae in their brood tubes had ripened ovaries in their abdominal segments, although no ovaries were observed in the females just after spawning embryos into the brood tubes. These reproductive characteristics indicated that the ovaries of females matured a second time during the brooding period for only about 1 wk to $10 \mathrm{~d}$, suggesting that females have the potential to reproduce at least twice. However, in the laboratory, females reproduced only once and died soon after they had finished brooding (Tsutsumi \& Kikuchi 1984). In the present follow-up study, female 
mortality after brooding in the field population was analysed with the data on synchronous reproduction shown in Fig. 8.

As mentioned above, females can mature their ovaries during the brooding period again. Therefore, the females emerging from brood tubes after brooding also should have mature ovaries, and be regarded as non-brooding mature females. Here, if female mortality after brooding was minor, the decrease in the density of brooding females caused by the finish of brooding would be followed by an increase in the density of non-brooding mature females. The changes in the density of non-brooding mature females, however, preceded or were synchronized with those of brooding females in the field population (Fig. 8). Thus, female mortality after brooding is considered also to be very high in the field population. In the present study, the Capitella capitata population reproduced synchronously twice from October to December. Since female mortality after brooding is considered to be very high, few females that contributed to the first peak of synchronous reproduction would have survived until the second peak occurred. These 2 synchronous reproductions therefore appear to be caused by 2 different groups of mature females.

The synchronous reproduction in the Capitella capitata population resulted in the synchronous recruitment of members to the size class at settlement (mostly to the class of 0.15 to $0.20 \mathrm{~mm}$ ) thoracic width immediately after the density of brooding females had reached its peak. Very many recruits were observed in the size-frequency distributions on 12 November and 10 December (Fig. 7). These newly formed peaks in the distribution have been treated as representative of a succession of cohorts.

Growth of each cohort was followed by tracing the changes of the modes in the size-frequency curves. In the present study, 4 cohorts were produced during the 3 mo from October to December (Fig. 9). Generation structure changes during this period were interpreted as follows, considering high female mortality after brooding and synchronous reproduction in the population.

Cohort 2 matured with a thoracic width of about 1.0 $\mathrm{mm}$ (mode) at the beginning of November, and produced Cohort 4, which recruited from 12 to 25 November. The first peak in the density of brooding females on 6 November (Fig. 8) resulted from the synchronous reproduction of Cohort 2. Almost all females and males of this cohort appeared to die soon after their first reproduction. It was already difficult to detect the size-frequency distribution of Cohort 2 in the population when Cohort 4 was recruiting. Cohort 4 grew to about $1.0 \mathrm{~mm}$ (mode) in thoracic width by 30 December, only about $6 \mathrm{wk}$ after its settlement, and

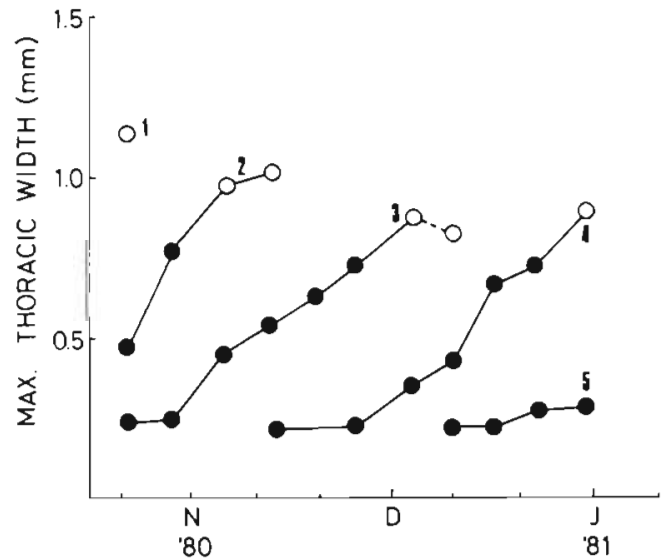

Fig. 9. Capitella capitata. Changes of modes in size-frequency distributions of each cohort. Numbers designate the cohorts described in the text. (O) Presence of brooding females and mature males in the cohort

some fully mature adults were also included in this cohort. Cohort 3 completed its life cycle out of phase with the cycles of Cohorts 2 and 4 . Cohort 3 recruited between 12 and 21 October, and grew to about 0.85 $\mathrm{mm}$ (mode) in thoracic width on 4 December. The synchronous reproduction of this cohort resulted in the second peak in the density of brooding females on 10 December (Fig. 8), when Cohort 5 was produced. Cohort 3 also took $6 \mathrm{wk}$ to complete its life cycle, and disappeared by the end of December. Thus, in the present study area, the population of Capitella capitata consisted of 2 cohorts with short and monotelic life cycles. The one was being recruited into the established population while the other had already fully matured. Both juveniles immediately after settlement and mature adults were, therefore, often found in the population simultaneously.

\section{DISCUSSION}

The population of Capitella capitata was made up of 2 cohorts with a short, monotelic life cycle, each reproducing synchronously (Fig. 9). Consequently, reproduction and mass recruitment were frequently observed, and brooding females and juveniles, just after settlement, were collected on almost every sampling occasion (Fig. $7 \& 8$ ). This type of generation structure and these reproductive characteristics were also observed in the population of C. capitata on Shioiri Flat adjacent to Tomoe Cove (Fig. 1) (Tsutsumi 1983). Since both populations of $C$. capitata reproduce throughout almost the whole year (Tsutsumi \& Kikuchi 1984), it is probable that the 2 cohorts that make up each population of $C$. capitata repeat monotelic, short life cycles throughout the year. Thus, the potential for 
population growth of C. capitata is considerably higher than that of many other annual or perennial benthic animals that are found in more stable habitats and that have relatively long prereproductive periods.

The generation structure of Capitella capitata, made up of 2 cohorts, has never previously been reported in population studies of Capitella species. Earlier studies were, however, based on only monthly or biweekly samplings (Grassle \& Grassle 1974, Warren 1976b, Oyenekan 1980, Chesney \& Tenore 1985), which make it very difficult to analyse the reproductive cycle and generation structure of species with such a short life cycle. Since a long breeding season, extending almost throughout the year, and early maturation are common life history characteristics among Capitella species found in habitats disturbed by organic pollution in various geographic regions (Reish 1961, 1974, Foret 1974, Grassle \& Grassle 1976, Grassle 1980, Yamamoto 1981, Tsutsumi \& Kikuchi 1984), the rapid growth of Capitella populations reported from other localities may also be caused by the same mechanisms as those observed in the present study.

The concentration of Capitella sp. populations in organically polluted areas as shown in Fig. $3 \& 4$ has previously been considered to be a reflection of the opportunistic characteristics of their life histories (Grassle \& Grassle 1974, Rosenberg 1976, Pearson \& Rosenberg 1978). Grassle \& Grassle (1974) adopted the definition of r-strategist proposed by Wilson \& Bossert (1971) as that of an opportunist adapted for life in a short-lived, unpredictable habitat by relying on a high $r$ to make use of ephemeral resources. In a new habitat such a species would: '(1) discover the habitat quickly, (2) reproduce rapidly to use up the resources before other, competing, species could exploit the habitat, and (3) disperse in search of other new habitats as the existing one began to grow unfavourable' (Wilson \& Bossert 1971). The population dynamics of the Capitella species reported by Grassle \& Grassle (1974), Rosenberg (1976), and McCall (1977) was, in fact, characterized by early recolonization of azoic areas, rapid population growth immediately after recolonization, and rapid decline in population sizes during the recovery process of other fauna. These characteristics appeared to support the hypothetical opportunism of these Capitella species. However, it is uncertain whether a biological interaction alone was responsible for the rapid decline in the population sizes of the Capitella species, because faunal replacement was followed by regression of organic pollution.

In the process of faunal recovery after defaunation of the present study area, Capitella capitata recolonized azoic areas adjacent to the fish farming cages, where a large amount of organic matter was continuously discharged by the farming activities, from late autumn to early winter. It maintained its high population densities until total defaunation occurred again during the early part of the following summer, in spite of subsequent recolonization by other polychaetes and bivalves (Tsutsumi \& Kikuchi 1983, present study). The population dynamics of Capitella species established in organically polluted areas may be stable as long as environmental conditions remain aerobic, even if other benthic animals coexist with them.

A series of laboratory experiments by Tenore using Capitella sp. I, which has, apparently, the most opportunistic life history (Grassle \& Grassle 1976), clearly demonstrated the nutritional control of individual growth rates, population sizes and annual production (Tenore 1977, 1981, 1983). Although the population size of this species oscillated cyclically during longterm experiments over approximately $2 \mathrm{yr}$, the size of laboratory populations consistently reflected the nutritional levels available (Chesney \& Tenore 1985, Tenore \& Chesney 1985). Such a relationship between nutritional conditions and some population parameters of the Capitella species was also supported by the laboratory experiments with Capitella capitata occurring in the present study area, using azoic sediments with various levels of organic matter (unpubl. data, results to be reported elsewhere). The body size of females at the time when they reproduced varied considerably, depending on nutritional conditions during the prereproductive period. Juveniles reared with organically polluted sediments from just below the fish farm grew into fully mature adults of approximately the same size as those in the field population after 1 mo in the laboratory, while juveniles fed on less polluted sediments collected from areas away from the fish farm did not even attain the body size (about $0.5 \mathrm{~mm}$ in thoracic width) at which they commenced sexual maturation, or else they only reached the minimum adult body size and produced just a few eggs, after 1 mo. Therefore, it appears that the absence of Capitella sp. in less organically polluted areas with stable environmental conditions, and the rapid decline of their populations in the benthic recovery process that follows the regression of pollution, can be ascribed to the shortage of organic intake and to their physiological demand for organic matter rather than to their poor ability to compete with other benthic animals considered to be less opportunistic. The physiological requirement for large amounts of organic matter to maintain individual growth and population size may concentrate the distribution of the Capitella species exclusively in heavily polluted areas.

The early recolonization of infaunal polychaetes, such as some Capitella species and spionid polychaetes with limited adult mobility in azoic areas, has been previously considered to arise from the pro- 
duction of planktonic larvae with the ability to disperse over a large area (Grassle \& Grassle 1974, Kikuchi \& Tanaka 1976, McCall 1977, Kikuchi 1979, Santos \& Simon 1980). However, Capitella species, in fact, produce lecithotrophic larvae with rather short planktonic stages that range from several hours to $1 \mathrm{~d}$ (Grassle \& Grassle 1976, Grassle 1980, Tsutsumi \& Kikuchi 1984). Although Capitella species occurring in organically polluted areas show the most rapid response to environmental variability, their reproductive modes and processes of larval development indicate that they possess limited ability to disperse by means of planktonic larvae.

The results of the present study suggest that a very small population of Capitella capitata persists somewhere adjacent to the heavily polluted area in the cove throughout the summer. Although such a refugial population was never discovered in summer, the sizefrequency distributions of the Capitella population shortly after recolonization involved not only newlysettled recruits but also some adult worms (Fig. 7). These adult worms must be derived from a population persisting in organically enriched areas near the fish farm throughout the summer. Their presence indicates that this species did not necessarily recolonize the area solely by means of planktonic larvae. Furthermore, colonization by a considerable number of $C$. capitata was sometimes found in a vessel containing sediment, hung about $1 \mathrm{~m}$ above the bottom under the floating fish cages in summer (unpubl. data). I observed that these worms emerged from the sediment and crawled up the inner sides of the bottle when conditions became anaerobic. At the fish farm, a large number of ropes were stretched along the bottom to anchor the floating cages. If juvenile or adult $C$. capitata can climb up the ropes to a level $1 \mathrm{~m}$ above the bottom, or if the larvae during their short pelagic period can settle in the sediment that accumulates among the barnacles attached to the ropes, a small population could remain under relatively aerobic conditions during the summer. Three adult $C$. capitata were actually collected from small ropes which had been set along the main ropes of the floating cages for $2 \mathrm{wk}$ in October 1980. Therefore, it seems likely that recolonization of the bottom in the immediately vicinity of the fish cages did not depend on the ability of $C$. capitata to disperse its larvae widely, but depended rather on the presence of a very small population that had taken refuge in the less anaerobic conditions prevailing on the fish cages ropes, a meter or so above the bottom. Such seed populations would not be detected by routine benthic sampling.

We should note the differences between the characteristics of the unpredictable environment assumed in the theories of life history strategy, especially in $\mathrm{r}$ - and
K-selection (Stearns 1976, Southwood 1977, Begon \& Mortimer 1981) and opportunism (Grassle \& Grassle 1974, McCall 1977), and the characteristics of environmental disturbances that actually occur in organically polluted areas. Dispersal or migratory strategies have been mainly seen as adaptations to environmental deterioration occurring randomly in time and space. On the other hand, in the present study, Capitella capitata in the organically polluted areas suffers from extremely deoxygenated bottom conditions which prevail over the whole area in which it is distributed from summer to early autumn, and remnants of these populations persisting throughout the summer have never been discovered in grab samplings from the cove. The extremely reduced environments would be, therefore, a seasonal rather than randomly occurring adversity for $C$. capitata. The life history of this polychaete does not, however, include a period of diapause (or dormancy) like that observed among plants and animals that occur in environments subject to seasonal adversity (Stearns 1976, Begon \& Mortimer 1981). It seems unlikely that the early recolonization by Capitella sp. in the process of faunal recovery after defaunation is directly associated with opportunistic life history strategies which stress widespread dispersal by means of planktonic larvae or dispersive strategies like those suggested in previous studies on life history strategy.

Recent studies on Capitella species indicate a relation between these species and the reduced conditions that tend to occur in organically enriched bottom sediments. Cuomo (1985) demonstrated that larval settlement of Capitella sp. I was promoted by sulphides, which are naturally occurring products of the anaerobic decomposition of organic matter, both in the laboratory and under semi-natural conditions. Warren (1984) showed that a Capitella species not only has an aerobic metabolic pathway but also an anaerobic one. Capitella species with a high potential for population growth and poor dispersal (or migratory) ability, occurring in organically polluted areas, may be regarded as organisms that positively select moderately reduced sediments as their habitats. That is, the organically polluted areas may not be temporary habitats that some Capitella species can utilize only during the process of benthic recovery immediately after defaunation, but rather such areas may be their native habitats. Future studies on population dynamics and physiology of the Capitella species will clarify further the reasons for their association with organically polluted areas.

Acknowledgements. I heartily thank Prof. T. Kikuchi, Dr. M. Tanaka, and Dr. S. Nojima for their innumerable suggestions, and Dr. J. P. Grassle for her critical comments, suggestions and improvements of the English text. I also thank Dr. A. M. Körner and Mr. R. K. Nakamura for their improvements of the English text. I am indebted to Messrs I. Goto and T. Samejima 
for their considerable assistance in sampling. This work was supported by a Grant-in-Aid for Scientific Research from the Ministry of Education, Science and Culture, Japan.

\section{LITERATURE CITED}

Begon, M., Mortimer, M. (1981). Population ecology. Blackwell Scientific Publications, London, p. 200

Bellan, G., Reish, D. J., Foret, J. P. (1972). The sublethal effects of a detergent on the reproduction, development, and settlement in the polychaetous annelid Capitella capitata. Mar. Biol. 14: 183-188

Cassie, R. M. (1954). Some uses of probability paper in the analysis of size frequency distributions. Aust. J. mar. Freshwat. Res. 5: 513-522

Chesney, E. J., Jr., Tenore, K. R. (1985). Oscillations of laboratory populations of the polychaete Capitella capitata (Type I): their cause and implications for natural populations. Mar. Ecol. Prog. Ser. 20: 289-296

Cuomo, M. C. (1985). Sulphide as a larval settlement cue for Capitella sp. I. Biogeochem. 1; 169-181

Foret, J. P. (1974). Étude des effets à long terme de quelques détergents sur la séquence du développement de la polychaette sédentaire Capitella capitata (Fabricius). Tethys 6: 751-778

Gadgil, M., Solbrig, O. T. (1972). The concept of $\mathrm{r}$ - and Kselection: evidence from wild flowers and some theoretical considerations. Am. Nat. 106: 14-31

Grassle, J. F., Grassle, J. P. (1974). Opportunistic life histories and genetic systems in marine benthic polychaetes. J. mar. Res. 32: 253-284

Grassle, J. P., Grassle, J. F. (1976). Sibling species in the marine pollution indicator Capitella (Polychaeta). Science 192: $567-569$

Grassle, J. F., Grassle, J. P. (1977). Temporal adaptations in sibling species of Capitella. In: Coull, B. C. (ed.) Ecology of marine benthos. Univ. South Carolina Press, Columbia, p. $177-189$

Grassle, J. F., Grassle, J. P. (1978). Life histories and genetic variation in marine invertebrates. In: Battaglia, B., Beardmore, J. A. (ed.) Marine organisms. Plenum Press, New York, p. 347-364

Grassle, J. P. (1980). Polychaete sibling species. In: Brinkhurst, R. O., Cook, D. G. (ed.) Aquatic oligochaete biology. Plenum Press, New York, p. 25-32

Grassle, J. P., Gelfman, C. E., Mills, S. W. (in press). Karyotypes of Capitella sibling species, and of several species in the related genera Capitellides and Capitomastus (Capitelidae: Polychaeta). Proc. Biol. Soc. Wash.

Halcrow, W., MacKay, D. W., Thornton, I. (1973). The distribution of trace metals and fauna in the Firth of Clyde in relation to the disposal of sewage siudge. J. mar. biol. Ass. U. K. 53: 721-739

Kikuchi, T. (1979). Some aspects of ecology, life cycle and taxonomy of the polychaete Capitella capitata, so called pollution indicator: a review. Benthos Res. 17/18: 33-51

Kikuchi, T., Tanaka, M. (1976). Some aspects on the ecology of a short-lived semelid bivalve, Theora lata (HINDS), with special reference to its opportunistic life history. Physiol. Ecol. Japan 17: 261-271

Kitamori, R. (1975). Benthos as a environmental indicator (S) with special reference to indicator species. In: the Special Committee of Japanese Ecological Society on Environmental Problems (ed.) Kankyo to Seibutsu Shihyo
(Environment and Indicator Species) Vol 2., Aquatic Environment. Kyoritsu Shuppan, Tokyo, p. 265-273

Kolmel, R. (1979). The annual cycle of macrozoobenthos: its community structures under the influence of oxygen deficiency in the Western Baltic. In: Naylor, E., Hartnoll, R. G. (ed.) Cyclic phenomena in marine plants and animals. 13th European Marine Biology Symposium. Pergamon Press, London, p. 19-28

McCall, P. L. (1977). Community patterns and adaptive strategies of the infaunal benthos of Long Island Sound. J. mar. Res. 35: 221-265

Oyenekan, J. A. (1980). Production and population dynamics of Capitella capitata. Arch. Hydrobiol. 98: 115-126

Pearson, T. H., Rosenberg, R. (1976). A comparative study of the effects on the marine environment of wastes from cellulose industries in Scotland and Sweden. Ambio 5: $77-79$

Pearson, T. H., Rosenberg, R. (1978). Macrobenthic succession in relation to organic enrichment and pollution of the environment. Oceanogr. mar. Biol. A. Rev. 16: 229-311

Reish, D. J. (1961). The use of the sediment bottle collector for monitoring polluted marine waters. Calif. Fish Game 47: 261-272

Reish, D. J. (1966). Relationship of polychaetes to varying dissolved oxygen concentrations. 3rd int. Conf. Water Pollut. Res. Munich. Sect. 3. Paper 10, Water Pollution Control Federation, Washington, D. C., p. 1-10

Reish, D. J. (1971). Effect of pollution abatement in Los Angeles harbors. Mar. Pollut. Bull. 2: 71-74

Reish, D. J. (1974). The establishment of laboratory colonies of polychaetous annelids. Thalassia jugosl. 10: 181-195

Reish, D. J. (1979). Bristle worms (Annelida: Polychaeta). In: Hart, C. W., Fuller, S. L. H. (ed.) Pollution ecology of estuarine invertebrates. Academic Press, New York, p. 78-125

Rosenberg, R. (1972). Benthic faunal recovery in a Swedish fjord following the closure of a sulphite pulp mill. Oikos 23: $92-108$

Rosenberg, R. (1976). Benthic faunal dynamics during succession following pollution abatement in a Swedish estuary Oikos 27: $414-427$

Santos, S. L., Simon, J. L. (1980). Marine soft-bottom community establishment following annual defaunation: larval or adult recruitment? Mar. Ecol. Prog. Ser. 2: 235-241

Stearns, S. C. (1976) Life history tactics: a review of the ideas. Q. Rev. Biol. 53: 3-47

Southwood, T. R. E. (1977). Habitat, the templet for ecological strategies? J. Anim. Ecol. 46: 337-365

Taylor, B. J. R. (1965). The analysis of polymodal frequency distributions. J. Anim. Ecol. 34: 445-452

Tenore, K. R. (1977). Growth of Capitella capitata cultured on various levels of detritus from different sources. Limnol. Oceanogr. 22: 936-941

Tenore, K. R. (1981). Organic nitrogen and caloric content of detritus. I. Utilization of the deposit-feeding polychaete, Capitella capitata. Estuar. coast. Shelf Sci. 12:39-47

Tenore, K. R. (1983). Organic nitrogen and caloric content of detritus. III. Effect on growth of a deposit feeding polychaete, Capitella capitata. Estuar. coast. Shelf Sci. 17 733-742

Tenore, K. R., Chesney, E. J., Jr. (1985). The effects of interaction of rate of food supply and population density on the bioenergetics of the opportunistic polychaete, Capitella capitata (type I). Limnol. Oceanogr. 30: 1188-1195

The Meteorological Agency of Japan (ed.) (1970). Manuals for marine observations. Oceanographical Society of Japan, Tokyo 
Tsutsumi, H. (1983). Preliminary report on population study of Capitella capitata (Polychaeta: Capitellidae) in Japan. Benthos Res. 24: 34-40

Tsutsumi, H., Kikuchi, T (1983). Benthic ecology of a small cove with seasonal oxygen depletion caused by organic pollution. Publ. Amakusa mar. biol. Lab. 7. 17-40

Tsutsumi, H., Kikuchi, T. (1984). Study of the life history of Capitella capitata (Polychaeta: Capitellidae) in Amakusa, South Japan including a comparison with other geographical regions. Mar. Biol. 80: 315-321

Ueno, S., Yamamoto, G. (1982). Physiological tolerance in the polychaetous annelids Capitella capitata and Paraprionospio pinnata. Benthos Res. 23: 60-68

Yamamoto, G. (1980). Ecological study on indicator species of eutrophic waters. Annual report of the study supported by the Grant from the Ministry of Education of Japan (Grant No. 257219$)$ in 1979, p. 82

Yamamoto, I. (1981). Ecological studies on Capitella capitata
(Polychaeta, Capitellidae). Master's thesis, University of Nagasaki

Wade, B. A., Antonio, L., Mahon, R. (1972). Increasing organic pollution in Kingston Harbour, Jamaica. Mar. Pollut. Bull. 3: 106-111

Warren, L. M. (1976a). A review of the genus Capitella (Polychaeta, Capitellidae). J. Zool, Lond. 180: 195-209

Warren, L. M. (1976b). A population study of the polychaete Capitella capitata at Plymouth. Mar. Biol. 38: 209-216

Warren, L. M. (1984). How intertidal polychaetes survive at low tide. In: Hutchings, P. A. (ed.) Proc. 1st Int. Polychaete Conf. Linn. Soc. N. S. W., Sydney, p. 238-253

Wilson, E. O., Bossert, W. H. (1971). A primer of population biology. Sinauer Associates, Stanford

Wu, B.-L. (1964). Subspecific differentiation and ecological characteristics of Capitella capitata (Fabricius, 1780) (Polychaeta, Capitellidae). Oceanol. Limnol. Sin. 6: 266-271

This article was presented by Professor T. Fenchel; it was accepted for printing on December 23, 1986 